\title{
Probiotics and Atopic Dermatitis: An Overview
}

\section{OPEN ACCESS}

Edited by:

Philip Arthur Mackowiak,

University of Maryland School

of Medicine, USA

Reviewed by:

Ravinder Nagpal,

Juntendo University Graduate School

of Medicine, Japan

Harsh Panwar,

Guru Angad Dev Veterinary

and Animal Sciences University, India

*Correspondence:

Yong-Ha Park

peter@ynu.ac.kr:

Jeongheui Lim

jeongheuilim@gmail.com

${ }^{\dagger}$ These authors have contributed equally to this work.

Specialty section: This article was submitted to Infectious Diseases,

a section of the journal

Frontiers in Microbiology

Received: 13 October 2015 Accepted: 29 March 2016

Published: 12 April 2016

Citation:

Rather IA, Bajpai VK, Kumar S, Lim J,

Paek WK and Park Y-H (2016)

Probiotics and Atopic Dermatitis: An

Overview. Front. Microbiol. 7:507.

doi: 10.3389/fmicb.2016.00507

\author{
Irfan A. Rather ${ }^{1 \dagger}$, Vivek K. Bajpai1t, Sanjay Kumar², Jeongheui Lim³ ${ }^{3 *}$, Woon K. Paek ${ }^{3}$ and \\ Yong-Ha Park ${ }^{1 *}$
}

${ }^{1}$ Department of Applied Microbiology and Biotechnology, School of Biotechnology, Yeungnam University, Gyeongsan, South Korea, ${ }^{2}$ Department of Clinical Studies, College of Veterinary Medicine, New Bolton Center University of Pennsylvania, Pennsylvania, PA, USA, ${ }^{3}$ National Science Museum, Ministry of Science, ICT and Future Planning, Daejeon, South Korea

Atopic dermatitis (AD) is a common, recurrent, chronic inflammatory skin disease that is a cause of considerable economic and social burden. Its prevalence varies substantially among different countries with an incidence rate proclaimed to reach up to $20 \%$ of children in developed countries and continues to escalate in developing nations. This increased rate of incidence has changed the focus of research on $A D$ toward epidemiology, prevention, and treatment. The effects of probiotics in the prevention and treatment of $A D$ remain elusive. However, evidence from different research groups show that probiotics could have positive effect on AD treatment, if any, that depend on multiple factors, such as specific probiotic strains, time of administration (onset time), duration of exposure, and dosage. However, till date we still lack strong evidence to advocate the use of probiotics in the treatment of $A D$, and questions remain to be answered considering its clinical use in future. Based on updated information, the processes that facilitate the development of $A D$ and the topic of the administration of probiotics are addressed in this review.

Keywords: atopic dermatitis, skin diseases, inflammation, clinical trials, probiotics

\section{INTRODUCTION}

Atopic Dermatitis (AD), also known as eczema, is a chronic inflammatory, relapsing, and noncontagious skin disease that is known to affect $\approx 20 \%$ of children in both developed and developing countries (Shaw et al., 2011; Deckers et al., 2012). AD represents one's first allergic reaction encountered in childhood and is recognized as a precursor for the development of a series of hypersensitivity reactions such as food allergies, asthma, and allergic rhinitis (Castro-Rodriguez, 2010; Finnbogadóttir et al., 2012; Carlsten et al., 2013; Silverberg and Simpson, 2013). Classical treatment guidelines for $\mathrm{AD}$ include hydrating topical treatment, topical glucocorticosteroids (Schmitt et al., 2010), topical calcineurin inhibitors, and concurrent adjuvant therapy, which includes UV radiations (UVA1 and UVB $311 \mathrm{~nm}$ ) (Williams and Grindlay, 2008; Gambichler et al., 2009; Majoie et al., 2009). Traditional therapeutic strategies have been efficacious in ameliorating the symptoms of $\mathrm{AD}$ in most patients (Lio et al., 2012). However, a more comprehensive and 
mechanistic understanding of the underlying immunological processes is needed to instigate the development of novel applicable treatment approaches for AD.

\section{GENETIC PREDISPOSITION TO AD AND UNDERLYING IMMUNOPATHOLOGICAL PROCESS}

Atopic dermatitis is a skin disease that is characterized by compromised skin barrier integrity, heightened inflammatory response against stimulants, and diminished antimicrobial responses that incite abnormal inflammation in the skin. The underlying mechanism and etiology of $\mathrm{AD}$ remain unexplored. $\mathrm{AD}$ is a complex skin problem caused by an interplay between genetic susceptibility and prenatal/postnatal environmental factors (Williams and Flohr, 2006). Genome wide screens have linked $\mathrm{AD}$ to several chromosomal loci, including $3 \mathrm{q} 21$, 5q31, and 11q13 (Lee et al., 2000; Bowcock and Cookson, 2004; Haagerup et al., 2004; Hoffjan and Epplen, 2005). The candidate genes interestingly encode immunomodulators and co-stimulatory proteins involved in T-cell activation, as well as cytokines involved in the regulation of $\operatorname{IgE}$ synthesis, such as interleukin-3, interleukin-4, interleukin-5, interleukin-11, and the granulocyte-macrophage colony-stimulating factor (GMCSF) (Fölster-Holst et al., 1998; Kawashima et al., 1998; Forrest et al., 1999; Leung and Bieber, 2003). A study identified loss-offunction non-sense mutations in the filaggrin gene (FLG) that is associated with AD (Marenholz et al., 2006; Palmer et al., 2006; Sandilands et al., 2007; Margolis et al., 2013). The FLG encodes a protein that is responsible for retaining moisture and protecting the skin from environmental allergens; therefore, it is crucial for maintaining skin barrier integrity.

Prenatal and postnatal maternal diet, gestational diabetes, exposure to microorganisms, and allergens are potential risk factors associated with the onset and development of $\mathrm{AD}$ (Cipriani et al., 2014). Several epidemiological and experimental evidences support the theory of "hygeine hypothesis" as the most reasonable explanation for the $\mathrm{AD}$ epidemics in last few decades (Martinez, 2001). The hygeine hypothesis suggests that changes in immunoregulatory infectious environment and the patterns of microbial exposure of children that are associated with Westernized culture are critical factors underlying the increasing severity and prevalence of atopic disorders. A study conducted by Strachan (1989) demonstrated an inverse correlation between sibship size and the subsequent risk of allergy, and it was recently confirmed by a broad international study involving more than 500,000 children in 52 countries (Strachan et al., 2015). Briefly, hygiene hypothesis inversely relates the prevalence of allergic diseases and urban lifestyles, high standard sanitary conditions, vaccinations, antibiotic administration, and small family size. Westernized lifestyle scales down infantile exposure to the allergens, which translates into decreased Th1-driven immune responses and favors less mature neonatal Th2-mediated immune systems, which may be the cause of the onset of allergic diseases (Strachan, 2000).

\section{PROBIOTICS AND PREVENTION OF ATOPIC DERMATITIS}

Probiotics are live microorganisms that, when administered in sufficient amounts, confer health benefits on the host (Hill et al., 2014). They barricade the epithelium and mucosal surfaces in the intestine, thereby preventing the adherence and invasion of pathogens (Servin and Coconnier, 2003). After birth the host receives primary microbial stimulus through the installation of gut microbiota or through exposure to specific bacterial strains. The establishment of microbial flora in the early postnatal period activates the innate and adaptive immune system, and the uninterrupted microbial stimulus serves to mature the gut mucosal immune system. Early compromised microbial stimulus may lead to reduced intestinal surface area, incoordination and alteration in the mucosal intermediary metabolism, a sensitive mucosal barrier, and a secretory mucosal IgA system (Gaskins, 1997; Cebra, 1999). An imbalance in Th1/ Th2 immune response has been related to the pathogenesis of allergic diseases (Romagnani et al., 1991; Romagnani, 2000; Schmidt-Weber and Blaser, 2004). Probiotics contribute to regulating allergic hypersensitivity reactions by suppressing the Th2 mediated response that helps in balancing Th1/ Th2 immune responses and by increasing Treg mediated immune responses (Feleszko et al., 2007; Kim et al., 2012; Kim J.Y. et al., 2013).

A large number of studies have explored the potential efficacy of probiotics in the prevention and treatment of $\mathrm{AD}$ (Pessi et al., 2000; Kalliomaki et al., 2001; Ouwehand et al., 2002; Hattori et al., 2003; Matsumoto et al., 2007; Park et al., 2008; Savilahti et al., 2008; Wickens et al., 2008; Adams, 2010; Batchelor et al., 2010; Chapman et al., 2011; Wickens et al., 2012; Morgan et al., 2014), yet the picture remains unclear and conflicting (Table 1). Lactobacillus rhamnosus GG (LGG) is the most frequently studied probiotic strain. AD prevention studies have been carried out on children at high risk of $\mathrm{AD}$, and probiotic administration was done 2-4 weeks prenatally to the pregnant mothers and postnatally to the infants for a 1year time period (Frei et al., 2015). The epidemiological study of a cohort from Norway investigated the potential association between the administration of probiotic milk during pregnancy and infancy period and the onset or establishment of atopic diseases such as $\mathrm{AD}$, rhinoconjunctivitis, and asthama. This study demonstrated an inverse correlation between the intake of probiotic milk products and the incidence of $\mathrm{AD}$; however, the certainty of the evidence is low (Bertelsen et al., 2014). Another study evaluated the impact of Bifidobacterium breve M$16 \mathrm{~V}$ and Bifidobacterium longum BB536 administration over the time period of 1 month prenatally, 6 months during infancy, and a period of 18 months follow up on the management of allergic diseases (Enomoto et al., 2014). The study concluded that the incidence of $\mathrm{AD}$ was lower in the probiotic administered cases than the controls. A study performed by Rautava et al. (2012) investigated the preventive effects of L. rhamnosus LPR, B. longum BL999, and L. paracasei ST11, during 2 months before and after the expected date of delivery. They reported less episodes of $\mathrm{AD}$ in the infants of mothers who received any of the probiotic supplements compared to the placebo group; 
TABLE 1 | Effect of probiotics (single or mixed culture) on treatment of Atopic Dermatitis (AD) in humans.

\begin{tabular}{|c|c|c|}
\hline Reference & Probiotics & Outcome \\
\hline Majamaa and Isolauri, 1997 & Lactobacillus rhamnosus strain GG & SCORAD score improvement $(P=0.008)$ \\
\hline Rosenfeldt et al., 2003 & L. rhamnosus + L. reuteri & Positive effect of probiotics seen in allergic subjects $(P=0.04)$ \\
\hline Kirjavainen et al., 2003 & L. rhamnosus strain GG or L. GG & SCORAD decrease $(P=0.02)$ \\
\hline Viljanen et al., 2005 & L. rhamnosus strain GG & Positive effect seen only in lgE-sensitized infants $(P=0.036)$ \\
\hline Weston et al., 2005 & L. fermentum & SCORAD decrease $(P=0.03)$ \\
\hline Passeron et al., 2006 & L. rhamnosus/synbiotics & No significant difference between synbiotics and placebo \\
\hline Sistek et al., 2006 & L. rhamnosus + B. lactis & Positive effect seen only in food-sensitized children $(P=0.047)$ \\
\hline Brouwer et al., 2006 & L. rhamnosus strain GG or L. rhamnosus & No significant difference between probiotics and placebo \\
\hline Fölster-Holst et al., 2006 & L. rhamnosus strain GG & No significant difference between probiotics and placebo \\
\hline Grüber et al., 2007 & L. rhamnosus strain GG & No significant difference between probiotics and placebo \\
\hline Roessler et al., 2008 & L. paracasei + L. acidophilus + B. lactis & No significant effects of probiotics \\
\hline Chernyshov, 2009 & L. rhamnosus 95\%, L. helveticus 5\% & $\begin{array}{l}\text { SCORAD decrease in subjects not used topical steroids was } \\
\text { shown only in probiotic group }(P<0.01)\end{array}$ \\
\hline Gerasimov et al., 2010 & L. acidophilus + B. lactis & SCORAD decrease $(P=0.001)$ \\
\hline Woo et al., 2010 & L. sakei & SCORAD decrease $(P=0.008)$ \\
\hline Cukrowska et al., 2010 & L. casei + L. paracasei & $\begin{array}{l}\text { Clinical improvement seen mostly in children with } \\
\text { lgE-dependent atopic eczema }\end{array}$ \\
\hline Gobel et al., 2010 & L. acidophilus, or B. lactis/- & No beneficial effects observed \\
\hline van der Aa et al., 2010 & B. breve/synbiotics & Improvement in IgE-sensitized infants $(P=0.04)$ \\
\hline Yoshida et al., 2010 & B. breve & SCORAD decrease $(P=0.034)$ \\
\hline Wu et al., 2011 & L. salivarius/ / synbiotics & SCORAD decrease at 8 week $(P=0.022)$ \\
\hline Farid et al., 2011 & mixture/synbiotics & SCORAD decrease $(P=0.001)$ \\
\hline Gore et al., 2012 & L. paracasei or Bifidobacterium & No significant difference between probiotics and placebo \\
\hline Yesilova et al., 2012 & $\begin{array}{l}\text { Bifidobacterium } \\
\text { bifidum }+L \text {. acidophilus }+L \text {. casei }+L \text {. salivarius }\end{array}$ & SCORAD decrease $(P=0.0015)$ \\
\hline Han et al., 2012 & L. plantarum & SCORAD decrease $(P=0.0015)$ \\
\hline lemoli et al., 2012 & L. salivarius; + B. breve & SCORAD decrease $(P<0.001)$ \\
\hline Drago et al., 2011 & L. salivarius & SCORAD decrease $(P<0.001)$ \\
\hline Niccoli et al., 2014 & L. salivarius LS01 & SCORAD and itch improvement \\
\hline
\end{tabular}

however, there was no difference in skin prick tests among the experimental groups (Rautava et al., 2012). A number of studies on LGG suggest that the combination of probiotic strains and prebiotic mixtures imposes positive effects in terms of preventing the onset of AD (Kukkonen et al., 2007; Mikael, 2013; Foolad and Armstrong, 2014). However, strong evidence to support the effectiveness of the administration of probiotics at a clinical level remains elusive (Meninghin et al., 2012; Foolad and Armstrong, 2014).

There are studies that state that the use of probiotics is ineffective in the management of $\mathrm{AD}$. The incidence of $\mathrm{AD}$ was investigated when the infants who had received probiotic strains of L. salivarius CUL61, L. paracasei CUL08, Bifidobacterium animalis subspecies lactis CUL34, and Bifidobacterium bifidum CUL20 reached 2 years of age, and the results were compared to those of toddlers who had not received the placebo. The administration of probiotics did not intervene in the development of AD (Allen et al., 2014).

\section{TREATMENT OF ATOPIC DERMATITIS}

Evidence supporting the use of probiotics for the treatment and prevention of $\mathrm{AD}$ is very limited. A restricted amount of evidence suggests that probiotics can decrease the severity of AD. A randomized, double-blind, placebo-controlled study investigated the effects of the use of the L. plantarum CJLP133 strain in the prevention of $\mathrm{AD}$ symptoms. The study was performed for a time period of 12 weeks among children who were one and 12 years old. It was found that there was an improvement in AD scores (SCORAD), with a concomitant decrease in IFN- $\gamma$, eosinophil, and Interleukin-4 counts (Han et al., 2012). Another randomized, double-blind, placebocontrolled study investigated the use of L. paracasei (LP), L. fermentum (LF), and LP+LF together in children, and it was observed that the SCORAD scores were lower in the group that received probiotics than those of the placebo group 4 months after discontinuing the probiotic treatment (Wang and Wang, 2015). Woo et al. (2010) compared children who received $L$. sakei supplementation to those who received a placebo in a double-blind, placebo-controlled trial. It was found that the supplementation of $L$. sakei was associated with substantial clinical improvement with concomitant decrease in chemokine levels (Woo et al., 2010). Previous meta-analyses evaluating the effects of probiotics on the treatment of $\mathrm{AD}$ have resulted in inconsistent results (Boyle et al., 2008; Lee et al., 2008; Michail et al., 2008; Kim et al., 2014). Of these meta-analyses, the most recent one concluded that probiotics significantly improved the 


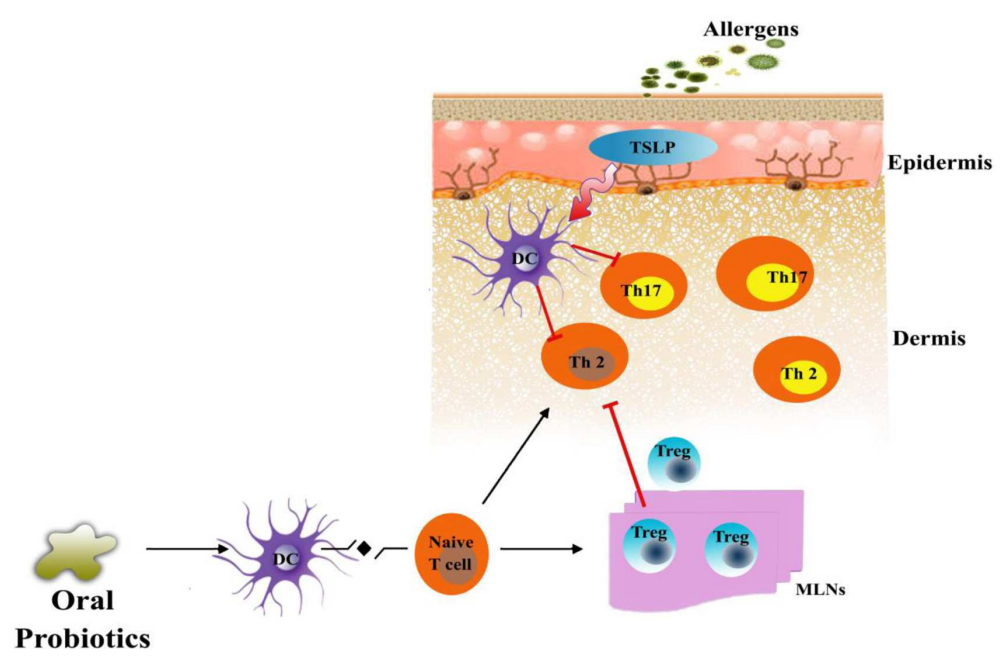

FIGURE 1 | Proposed mechanism of probiotics in an animal model of AD. Exposure of atopic skin to a potential allergen enhances the expression of thymic stromal lymphopoietin (TSLP) that is known to activate dendritic cells (DC). Stimulated dendritic cell direct differentiation of naïve T-cell into Th2 cells and Th17 cells which, are known as the mediators of allergic inflammation in skin. Probiotics could inhibit the allergic inflammation by increasing the population of regulatory $T$ cells (Tregs) in the mesenteric lymph nodes of patients. These Tregs could migrate to the site of inflammation and suppress the Th2 and Th17 mediated allergic response or directly reduce the expression of TSLP.

SCORAD index in patients aged 1 year or older with AD (mean difference, -4.51 ; [95\% CI, -6.78 to -2.24 ]; Kim et al., 2014), but the clinical significance of these findings has been questioned, and therefore, the role of probiotics in the treatment of $\mathrm{AD}$ has not been definitively established.

\section{MECHANISTIC INSIGHTS INTO FUNCTIONING OF PROBIOTICS}

The discovery of Th17 cells as the mediators of allergic inflammation in a mouse model of asthama superseded the previous modes of action of probiotics against allergic diseases (Feleszko et al., 2007). The application of probiotics reduced the inflammation by suppressing the levels of INF- $\gamma$, IL-4, and Th17 cells in splenic $\mathrm{CD}_{4}$ T-cells and increasing the expression of IL-10 and Treg-related cytokines in mesenteric lymph nodes as shown in Figure 1 (Jan et al., 2012). Probiotics also impose an inhibitory effect on the maturation of dendritic cells and, therefore, inhibit naive T-cells from differentiating into Th2 cells, which triggers inflammation in the skin (Kwon et al., 2010; Weiss et al., 2011). The differentiation of naïve $\mathrm{T}$ cells mediated by dendritic cells are known to be regulated by thymic stromal lymphopoietin (TSLP), a process that could be inhibited by probiotics (Weiss et al., 2011). Kim et al. (2013a,b) confirms the involvement of dendritic cells, following the transfer of mature dendritic cells in mice, in the suppression of allergic disease by probiotics.

\section{CONCLUSION}

Probiotics for the prevention or intervention of $\mathrm{AD}$ is a vast underestimated area of research; and as a result, there is no reliable evidence to date that strongly supports their safe application. In spite of the weak evidence, a considerable number of clinicians prescribe the use of probiotics for the prevention of eczema. The regular instillation of probiotics in daily use at an early age could help in preventing the initiation of eczema. However, several variables, such as the use of antibiotics, prenatal and postnatal diet, mode of delivery, and surrounding allergenic environment in the home, could impact the earlylife colonization of probiotic strains. Nevertheless, the clinical administration of probiotics may become more widespread if the remaining questions are answered with strong evidence: what type of probiotic strain should be used? What dosage and time of administration should be used? At what time of life is the use of probiotics more efficacious? And most importantly, should the use of probiotics be personalized? Current analysis of the role of probiotics in the prevention of $\mathrm{AD}$ reveals that a positive effect may be related to the type of probiotic strain used, the method of administration, onset time, as well as the dose size and duration of treatment. However, these uncertainties need to be further clarified before corroborating the preventive impact of probiotics in the prevention and/ or treatment of $\mathrm{AD}$.

\section{AUTHOR CONTRIBUTIONS}

IR and VB designed and wrote the manuscript, JL and WP conception and design the outline, SK and YK did the critical review and approved the manuscript.

\section{FUNDING}

Authors wish to thank National Research Foundation of Korea (2013M3A9A5047052, 2008-2004707, and 2012-0006701). 


\section{REFERENCES}

Adams, C. A. (2010). The probiotic paradox: live and dead cells are biological response modifiers. Nutr. Res. Rev. 23, 37-46.

Allen, S. J., Jordan, S., Storey, M., Thornton, C. A., Gravenor, M. B., Garaiova, I., et al. (2014). Probiotics in the prevention of eczema: a randomised controlled trial. Arch. Dis. Child. 99, 1014-1019. doi: 10.1136/archdischild-2013-305799

Batchelor, J. M., Grindlay, D. J., and Williams, H. C. (2010). What's new in atopic eczema? An analysis of systematic reviews published in 2008 and 2009. Clin Exp. Dermatol. 35, 823-827. doi: 10.1111/j.1365-2230.2010.03901.x

Bertelsen, R. J., Brantsæter, A. L., Magnus, M. C., Haugen, M., Myhre, R., Jacobsson, B., et al. (2014). Probiotic milk consumption in pregnancy and infancy and subsequent childhood allergic diseases. J. Allergy Clin. Immunol. 133, 165-171. doi: 10.1016/j.jaci.2013.07.032

Bowcock, A. M., and Cookson, W. O. (2004). The genetics of psoriasis, psoriatic arthritis and atopic dermatitis. Hum. Mol. Genet. 13, R43-R55. doi: $10.1093 / \mathrm{hmg} / \mathrm{ddh} 094$

Boyle, R. J., Bath-Hextall, F. J., Leonardi-Bee, J., Murrell, D. F., and Tang, M. L. (2008). Probiotics for treating eczema. Cochrane Database Syst. Rev. 8:CD006135. doi: 10.1002/14651858.CD006135

Brouwer, M. L., Wolt-Plompen, S. A., Dubois, A. E., van der Heide, S., Jansen, D. F., Hoijer, M. A., et al. (2006). No effects of probiotics on atopic dermatitis in infancy: a randomized placebo-controlled trial. Clin. Exp. Allergy 36, 899-906. doi: 10.1111/j.1365-2222.2006.02513.x

Carlsten, C., Dimich-Ward, H., Ferguson, A., Watson, W., Rousseau, R., Dybuncio, A., et al. (2013). Atopic dermatitis in a high-risk cohort: natural history, associated allergic outcomes, and risk factors. Ann. Allergy Asthma Immunol. 110, 24-28. doi: 10.1016/j.anai.2012.10.005

Castro-Rodriguez, J. A. (2010). The Asthma Predictive Index: a very useful tool for predicting asthma in young children. J. Allergy Clin. Immunol. 126, 212-216. doi: 10.1016/j.jaci.2010.06.032

Cebra, J. J. (1999). Influences of microbiota on intestinal immune system development. Am. J. Clin. Nutr. 69, 1046-1051.

Chapman, C. M., Gibson, G. R., and Rowland, I. (2011). Health benefits of probiotics: are mixtures more effective than single strains? Eur. J. Nutr. 50, 1-17. doi: 10.1007/s00394-010-0166-z

Chernyshov, P. V. (2009). Randomized, placebo-controlled trial on clinical and immunologic effects of probiotic containing Lactobacillus rhamnosus R0011 and L. helveticus R0052 in infants with atopic dermatitis. Microb. Ecol. Health Dis. 21, 228-232. doi: 10.3109/08910600903444234

Cipriani, F., Dondi, A., and Ricci, G. (2014). Recent advances in epidemiology and prevention of atopic eczema. Pediatr. Allergy Immunol. 25, 630-638. doi: 10.1111/pai.12309

Cukrowska, B., Ceregra, A., Klewicka, E., Slizewska, K., Motyl, I., and Libudzisz, Z. (2010). Probiotic Lactobacillus casei and Lactobacillus paracasei strains in treatment of food allergy in children. Prz. Pediatryczny 40, 21-25.

Deckers, I. A., McLean, S., Linssen, S., Mommers, M., van Schayck, C. P., and Sheikh, A. (2012). Investigating international time trends in the incidence and prevalence of atopic eczema 1990-2010: a systematic review of epidemiological studies. PLoS ONE 7:e39803. doi: 10.1371/journal.pone.0039803

Drago, L., Iemoli, E., Rodighiero, V., Nicola, L., De Vecchi, E., and Piconi, S. (2011). Effects of Lactobacillus salivarius LS01 (DSM 22775) treatment on adult atopic dermatitis: a randomized placebo-controlled study. Int. J. Immunopathol. Pharmacol. 24, 1037-1048.

Enomoto, T., Sowa, M., Nishimori, K., Shimazu, S., Yoshida, A., Yamada, K., et al. (2014). Effects of bifidobacterial supplementation to pregnant women and infants in the prevention of allergy development in infants and on fecal microbiota. Allergol. Int. 63, 575-585. doi: 10.2332/allergolint.13-OA-0683

Farid, R., Ahanchian, H., Jabbari, F., and Moghiman, T. (2011). Effect of a new synbiotic mixture on atopic dermatitis in children: a randomized-controlled trial. Iran. J. Pediatr. 21, 225-230.

Feleszko, W., Jaworska, J., Rha, R. D., Steinhausen, S., Avagyan, A., Jaudszus, A., et al. (2007). Probiotic-induced suppression of allergic sensitization and airway inflammation is associated with an increase of $\mathrm{T}$ regulatory-dependent mechanisms in a murine model of asthma. Clin. Exp. Allergy 37, 498-505. doi: 10.1111/j.1365-2222.2006.02629.x

Finnbogadóttir, A. F., Árdal, B., Eiríksson, H., Hrafnkelsson, B., Valdimarsson, H., Lúóvíksson, B. R., et al. (2012). A long-term follow-up of allergic diseases in Iceland. Pediatr. Allergy Immunol. 23, 181-185. doi: 10.1111/j.13993038.2011.01234.x

Fölster-Holst, R., Moises, H. W., Yang, L., Fritsch, W., Weissenbach, J., and Christophers, E. (1998). Linkage between atopy and the $\operatorname{IgE}$ high-affinity receptor gene at 11q13 in atopic dermatitis families. Hum. Genet. 102, 236-239. doi: $10.1007 / \mathrm{s} 004390050685$

Fölster-Holst, R., Müller, F., Schnopp, N., Abeck, D., Kreiselmaier, I., Lenz, T., et al. (2006). Prospective, randomized controlled trial on Lactobacillus rhamnosus in infants with moderate to severe atopic dermatitis. Br. J. Dermatol. 155, 1256-1261. doi: 10.1111/j.1365-2133.2006.07558.x

Foolad, N., and Armstrong, A. W. (2014). Prebiotics and probiotics: the prevention and reduction in severity of atopic dermatitis in children. Benef. Microbes 5 , 151-160. doi: 10.3920/BM2013.0034

Forrest, S., Dunn, K., Elliott, K., Fitzpatrick, E., Fullerton, J., McCarthy, M., et al. (1999). Identifying genes predisposing to atopic eczema. J. Allergy Clin. Immunol. 104, 1066-1070. doi: 10.1016/S0091-6749(99)70090-4

Frei, R., Akdis, M., and O'Mahony, L. (2015). Prebiotics, probiotics, synbiotics, and the immune system: experimental data and clinical evidence. Curr. Opin. Gastroenterol. 31, 153-158. doi: 10.1097/MOG.0000000000000151

Gambichler, T., Othlinghaus, N., Tomi, N. S., Holland-Letz, T., Boms, S., Skrygan, M., et al. (2009). Medium-dose ultraviolet (UV) Al vs. narrowband UVB phototherapy in atopic eczema: a randomized crossover study. Br. J. Dermatol. 160, 652-658. doi: 10.1111/j.1365-2133.2008. 08984.x

Gaskins, H. R. (1997). "Immunological aspects of host/microbiota interactions at the intestinal epithelium," in Gastrointestinal Microbiology, eds R. I. Mackie, B. A. White, and R. E. Isaacson (New York, NY: International Thomson Publishing), 537-587.

Gerasimov, S. V., Vasjuta, V. V., Myhovych, O. O., and Bondarchuk, L. I. (2010). Probiotic supplement reduces atopic dermatitis in preschool children: a randomized, doubleblind, placebo-controlled, clinical trial. Am. J. Clin. Dermatol. 11, 351-361. doi: 10.2165/11531420-000000000-00000

Gobel, R., Larsen, N., Molgaard, C., Jakobsen, M., and Michaelsen, K. F. (2010). Probiotics to young children with atopic dermatitis: a randomized placebocontrolled trial. Int. J. Probiotics Prebiotics 5, 53-60.

Gore, C., Custovic, A., Tannock, G., Munro, K., Kerry, G., Johnson, K., et al. (2012). Treatment and secondary prevention effects of the probiotics Lactobacillus paracasei or Bifidobacterium lactis on early infant eczema: randomized controlled trial with follow-up until age 3 years. Clin. Exp. Allergy 42, 112-122. doi: 10.1111/j.1365-2222.2011.03885.x

Grüber, C., Wendt, M., Sulser, C., Lau, S., Kulig, M., Wahn, U., et al. (2007). Randomized, placebo-controlled trial of Lactobacillus rhamnosus GG as treatment of atopic dermatitis in infancy. Allergy 62, 1270-1276. doi: 10.1111/j.1398-9995.2007.01543.x

Haagerup, A., Bjerke, T., Schiøtz, P. O., Dahl, R., Binderup, H. G., Tan, Q., et al. (2004). Atopic dermatitis - a total genomes can for susceptibility genes. Acta Derm. Venereol. 84, 346-352. doi: 10.1080/000155504100 34426

Han, Y., Kim, B., Ban, J., Lee, J., Kim, B. J., Choi, B. S., et al. (2012). A randomized trial of Lactobacillus plantarum CJLP133 for the treatment of atopic dermatitis. Pediatr. Allergy Immunol. 23, 667-673. doi: 10.1111/pai.12010

Hattori, K., Yamamoto, A., Sasai, M., Taniuchi, S., Kojima, T., Kobayashi, Y., et al. (2003). Effects of administration of bifidobacteria on fecal microflora and clinical symptoms in infants with atopic dermatitis. Arerugi 52, 20-30.

Hill, C., Guarner, F., Reid, G., Gibson, G. R., Merenstein, D. J., Pot, B., et al. (2014). Expert consensus document: the International Scientific Association for Probiotics and Prebiotics consensus statement on the scope and appropriate use of the term probiotic. Nat. Rev. Gastroenterol. Hepatol. 11, 506-514. doi: 10.1038/nrgastro.2014.66

Hoffjan, S., and Epplen, J. T. (2005). The genetics of atopic dermatitis: recent findings and future options. J. Mol. Med. 83, 682-692. doi: 10.1007/s00109-0050672-2

Iemoli, E., Trabattoni, D., Parisotto, S., Borgonovo, L., Toscano, M., Rizzardini, G., et al. (2012). Probiotics reduce gut microbial translocation and improve adult atopic dermatitis. J. Clin. Gastroenterol. 46, S33-S40. doi: 10.1097/MCG.0b013e31826a8468

Jan, R. L., Yeh, K. C., Hsieh, M. H., Lin, Y. L., Kao, H. F., Li, P. H., et al. (2012). Lactobacillus gasseri suppresses Th17 pro-inflammatory response and 
attenuates allergen-induced airway inflammation in a mouse model of allergic asthma. Br. J. Nutr. 108, 130-139. doi: 10.1017/S0007114511005265

Kalliomaki, M., Salminen, S., Arvilommi, H., Kero, P., Koskinen, P., and Isolauri, E. (2001). Probiotics in primary prevention of atopic disease: a randomised placebo-controlled trial. Lancet 357, 1076-1079. doi: 10.1016/S0140-6736(00)04259-8

Kawashima, T., Noguchi, E., Arinami, T., Yamakawa-Kobayashi, K., Nakagawa, H., Otsuka, F., et al. (1998). Linkage and association of an interleukin 4 gene polymorphism with atopic dermatitis in Japanese families. J. Med. Genet. 35, 502-504. doi: 10.1136/jmg.35.6.502

Kim, H. J., Kim, H. Y., Lee, S. Y., Seo, J. H., Lee, E., and Hong, S. J. (2013a). Clinical efficacy and mechanism of probiotics in allergic diseases. Korean J. Pediatr. 56, 369-376. doi: 10.3345/kjp.2013.56.9.369

Kim, H. J., Kim, Y. J., Kang, M. J., Seo, J. H., Kim, H. Y., Jeong, S. K., et al. (2012). A novel mouse model of atopic dermatitis with epicutaneous allergen sensitization and the effect of Lactobacillus rhamnosus. Exp. Dermatol. 21, 672-675. doi: 10.1111/j.1600-0625.2012.01539.x

Kim, H. J., Kim, Y. J., Lee, S. H., Kang, M. J., Yu, H. S., Jung, Y. H., et al. (2013b). Effects of Lactobacillus rhamnosus on asthma with an adoptive transfer of dendritic cells in mice. J. Appl. Microbiol. 115, 872-879. doi: 10.1111/jam.12268

Kim, J. Y., Park, B. K., Park, H. J., Park, Y. H., Kim, B. O., and Pyo, S. (2013). Atopic dermatitis-mitigating effects of new Lactobacillus strain, Lactobacillus sakei probio 65 isolated from Kimchi. J. Appl. Microbiol. 115, 517-526. doi: 10.1111/jam.12229

Kim, S. O., Ah, Y. M., Yu, Y. M., Choi, K. H., Shin, W. G., and Lee, J. Y. (2014). Effects of probiotics for the treatment of atopic dermatitis: a meta-analysis of randomized controlled trials. Ann. Allergy Asthma Immunol. 113, 217-226. doi: 10.1016/j.anai.2014.05.021

Kirjavainen, P. V., Salminen, S. J., and Isolauri, E. (2003). Probiotic bacteria in the management of atopic disease: underscoring the importance of viability. J. Pediatr. Gastroenterol. Nutr. 36, 223-227. doi: 10.1097/00005176-20030200000012

Kukkonen, K., Savilahti, E., Haahtela, T., Juntunen-Backman, K., Korpela, R., Poussa, T., et al. (2007). Probiotics and prebiotic galactooligosaccharides in the prevention of allergic diseases: a randomized, double-blind, placebo-controlled trial. J. Allergy Clin. Immunol. 119, 192-198. doi: 10.1016/j.jaci.2006.09.009

Kwon, H. K., Lee, C. G., So, J. S., Chae, C. S., Hwang, J. S., Sahoo, A., et al. (2010). Generation of regulatory dendritic cells and CD4+Foxp3 $+\mathrm{T}$ cells by probiotics administration suppresses immune disorders. Proc. Natl. Acad. Sci. U.S.A. 107, 2159-2164. doi: 10.1073/pnas.0904055107

Lee, J., Seto, D., and Bielory, L. (2008). Meta-analysis of clinical trials of probiotics for prevention and treatment of pediatric atopic dermatitis. J. Allergy Clin. Immunol. 121, 116-121. doi: 10.1016/j.jaci.2007.10.043

Lee, Y. A., Wahn, U., Kehrt, R., Tarani, L., Businco, L., Gustafsson, D., et al. (2000). A major susceptibility locus for atopic dermatitis maps to chromosome $3 \mathrm{q} 21$. Nat. Genet. 26, 470-473. doi: 10.1038/82625

Leung, D. Y., and Bieber, T. (2003). Atopic dermatitis. Lancet 361, 151-160. doi: 10.1016/S0140-6736(03)12193-9

Leung, D. Y. M. (2003). Infection in atopic dermatitis. Curr. Opin. Pediatr. 15, 399-404. doi: 10.1097/00008480-200308000-00008

Lio, P. A., Lee, M., LeBovidge, J., Timmons, K. G., and Schneider, L. (2012). Clinical management of atopic dermatitis: practical highlights and updates from the atopic dermatitis practice parameter. J. Allergy Clin. Immunol. Pract. 2, 361-369. doi: 10.1016/j.jaip.2014.02.015

Majamaa, H., and Isolauri, E. (1997). Probiotics: a novel approach in the management of food allergy. J. Allergy Clin. Immunol. 99, 179-185. doi: 10.1016/S0091-6749(97)70093-9

Majoie, I. M., Oldhoff, J. M., van Weelden, H., Laaper-Ertmann, M., Bousema, M. T., Sigurdsson, V., et al. (2009). Narrowband ultraviolet B and medium-dose ultraviolet $\mathrm{A} 1$ are equally effective in the treatment of moderate to severe atopic dermatitis. J. Am. Acad. Dermatol. 60, 77-84. doi: 10.1016/j.jaad.2008.08.048

Marenholz, I., Nickel, R., Rüschendorf, F., Schulz, F., Esparza-Gordillo, J., Kerscher, T., et al. (2006). Filaggrin loss-of-function mutations predispose to phenotypes involved in the atopic march. J. Allergy Clin. Immunol. 118, 866-871. doi: 10.1016/j.jaci.2006.07.026

Margolis, D. J., Gupta, J., Apter, A. J., Ganguly, T., Hoffstad, O., Papadopoulos, M., et al. (2013). Filaggrin-2 variation is associated with more persistent atopic dermatitis in African American subjects. J. Allergy Clin. Immunol. 133, 784-789. doi: 10.1016/j.jaci.2013.09.015

Martinez, F. D. (2001). The coming-of-age of the hygiene hypothesis. Respir. Res. 2, 129-132. doi: 10.1186/rr48

Matsumoto, M., Aranami, A., Ishige, A., Watanabe, K., and Benno, Y. (2007). LKM512 yogurt consumption improves the intestinal environment and induces the T-helper type 1 cytokine in adult patients with intractable atopic dermatitis. Clin. Exp. Allergy 37, 358-370. doi: 10.1111/j.1365-2222.2007.02642.x

Meninghin, F., Fabiano, V., Mameli, C., and Zuccotti, G. V. (2012). Probiotics and atopic dermatitis in children. Pharmaceuticals 5, 727-744. doi: $10.3390 /$ ph5070727

Mikael, H. (2013). Probiotics and prebiotics in preventing food allergy and eczema. Curr. Opin. Allergy Clin. Immunol. 13, 280-286. doi: 10.1097/ACI.0b013e328360ed66

Michail, S. K., Stolfi, A., Johnson, T., and Onady, G. M. (2008). Efficacy of probiotics in the treatment of pediatric atopic dermatitis: a meta-analysis of randomized controlled trials. Ann. Allergy Asthma Immunol. 101, 508-516. doi: 10.1016/S1081-1206(10)60290-6.

Morgan, A. R., Han, D. Y., Wickens, K., Barthow, C., Mitchell, E. A., Stanley, T. V., et al. (2014). Differential modification of genetic susceptibility to childhood eczema by two probiotics. Clin. Exp. Allergy 44, 1255-1265. doi: $10.1111 /$ cea. 12394

Niccoli, A. A., Artesi, A. L., Candio, F., Ceccarelli, S., Cozzali, R., Ferraro, L., et al. (2014). Preliminary results on clinical effects of probiotic Lactobacillus salivarius LS01 in children affected by atopic dermatitis. J. Clin. Gastroenterol. 48, S34-S36. doi: 10.1097/MCG.0000000000000233

Ouwehand, A. C., Salminen, S., and Isolauri, E. (2002). Probiotics: an overview of beneficial effects. Antonie Van Leeuwenhoek 82, 279-289. doi: 10.1023/A:1020620607611

Palmer, C. N., Irvine, A. D., Terron-Kwiatkowski, A., Zhao, Y., Liao, H., Lee, S. P., et al. (2006). Common loss-of-function variants of the epidermal barrier protein filaggrin are a major predisposing factor for atopic dermatitis. Nat. Genet. 38, 441-446. doi: 10.1038/ng1767

Park, C. W., Youn, M., Jung, Y. M., Kim, H., Jeong, Y., Lee, H. K., et al. (2008). New functional probiotic Lactobacillus sakei probio 65 alleviates atopic symptoms in the mouse. J. Med. Food 11, 405-412. doi: 10.1089/jmf.2007. 0144

Passeron, T., Lacour, J. P., Fontas, E., and Ortonne, J. P. (2006). Prebiotics and synbiotics: two promising approaches for the treatment of atopic dermatitis in children above 2 years. Allergy 61, 431-437. doi: 10.1111/j.13989995.2005.00956.X

Pessi, T., Sutas, Y., Hurme, M., and Isolauri, E. (2000). Interleukin-10 generation in atopic children following oral Lactobacillus rhamnosus GG. Clin. Exp. Allergy 30, 1804-1808. doi: 10.1046/j.1365-2222.2000.00948.x

Rautava, S., Kainonen, E., Salminen, S., and Isolauri, E. (2012). Maternal probiotic supplementation during pregnancy and breast-feeding reduces the risk of eczema in the infant. J. Allergy Clin. Immunol. 130, 1355-1360. doi: 10.1016/j.jaci.2012.09.003

Roessler, A., Friedrich, U., Vogelsang, H., Bauer, A., Kaatz, M., Hipler, U. C., et al. (2008). The immune system in healthy adults and patients with atopic dermatitis seems to be affected differently by a probiotic intervention. Clin. Exp. Allergy 38, 93-102.

Romagnani, S. (2000). T-cell subsets (Th1 versus Th2). Ann. Allergy Asthma Immunol. 85, 9-18. doi: 10.1016/S1081-1206(10)62426-X

Romagnani, S., Maggi, E., Parronchi, P., Macchia, D., Piccinni, M. P., and Ricci, M. (1991). Increased numbers of Th2-like CD4+ T cells in target organs and in the allergen-specific repertoire of allergic patients. Possible role of IL-4 produced by non-T cells. Int. Arch. Allergy Appl. Immunol. 94, 133-136. doi: $10.1159 / 000235344$

Rosenfeldt, V., Benfeldt, E., Nielsen, S. D., Michaelsen, K. F., Jeppesen, D. L., Valerius, N. H., et al. (2003). Effect of probiotic Lactobacillus strains in children with atopic dermatitis. J. Allergy Clin. Immunol. 111, 389-395. doi: 10.1067/mai.2003.389

Sandilands, A., Terron-Kwiatkowski, A., Hull, P. R., O’Regan, G. M., Clayton, T. H., Watson, R. M., et al. (2007). Comprehensive analysis of the gene encoding filaggrin uncovers prevalent and rare mutations in ichthyosis vulgaris and atopic eczema. Nat. Genet. 39, 650-654. doi: 10.1038/ng2020 
Savilahti, E., Kuitunen, M., and Vaarala, O. (2008). Pre and probiotics in the prevention and treatment of food allergy. Curr. Opin. Allergy Clin. Immunol. 8, 243-248. doi: 10.1097/ACI.0b013e3282ffb134

Schmidt-Weber, C. B., and Blaser, K. (2004). Immunological mechanisms in specific immunotherapy. Springer Semin. Immunopathol. 25, 377-390. doi: 10.1007/s00281-003-0147-x

Schmitt, J., Schäkel, K., Fölster-Holst, R., Bauer, A., Oertel, R., Augustin, M., et al. (2010). Prednisolone vs. ciclosporin for severe adult eczema. An investigatorinitiated double-blind placebo- controlled multicentre trial. $\mathrm{Br}$. J. Dermatol. 162, 661-668. doi: 10.1111/j.1365-2133.2009.09561.x

Servin, A. L., and Coconnier, M. H. (2003). Adhesion of probiotic strains to the intestinal mucosa and interaction with pathogens. Best Pract. Res. Clin. Gastroenterol. 17, 741-754. doi: 10.1016/S1521-6918(03)00052-0

Shaw, T. E., Currie, G. P., Koudelka, C. W., and Simpson, E. L. (2011). Eczema prevalence in the United States: data from the 2003 National Survey of Children's Health. J. Invest. Dermatol. 131, 67-73. doi: 10.1038/jid.2010.251

Silverberg, J. I., and Simpson, E. L. (2013). Association between severe eczema in children and multiple comorbid conditions and increased healthcare utilization. Pediatr. Allergy Immunol. 24, 476-486. doi: 10.1111/pai. 12095

Sistek, D., Kelly, R., Wickens, K., Stanley, T., Fitzharris, P., and Crane, J. (2006). Is the effect of probiotics on atopic dermatitis confined to food sensitized children? Clin. Exp. Allergy 36, 629-633. doi: 10.1111/j.1365-2222.2006.02485.x

Strachan, D. P. (1989). Hay fever, hygiene, and household size. BMJ 299, 12591260. doi: 10.1136/bmj.299.6710.1259

Strachan, D. P. (2000). Family size, infection and atopy: the first decade of the "hygiene hypothesis." Thorax 55, S2-S10. doi: 10.1136/thorax.55.suppl_1.S2

Strachan, D. P., Aït-Khaled, N., Foliaki, S., Mallol, J., Odhiambo, J., Pearce, N., et al. (2015). Siblings, asthma, rhinoconjunctivitis and eczema: a worldwide perspective from the International Study of Asthma and Allergies in Childhood. Clin. Exp. Allergy 45, 126-136. doi: 10.1111/cea.12349

van der Aa, L. B., Heymans, H. S., van Aalderen, W. M., Sillevis Smitt, J. H., Knol, J., Ben Amor, K., et al. (2010). Effect of a new synbiotic mixture on atopic dermatitis in infants: a randomized-controlled trial. Clin. Exp. Allergy 40:795-804. doi: 10.1111/j.1365-2222.2010.03465.x

Viljanen, M., Savilahti, E., Haahtela, T., Juntunen-Backman, K., Korpela, R., Poussa, T., et al. (2005). Probiotics in the treatment of atopic eczema/dermatitis syndrome in infants: a double-blind placebo -controlled trial. Allergy 60, 494500. doi: 10.1111/j.1398-9995.2004.00514.x

Wang, I. J., and Wang, J. Y. (2015). Children with atopic dermatitis show clinical improvement after Lactobacillus exposure. Clin. Exp. Allergy 45, 779-787. doi: 10.1111/cea.12489

Weiss, G., Christensen, H. R., Zeuthen, L. H., Vogensen, F. K., Jakobsen, M., and Frøkiær, H. (2011). Lactobacilli and bifidobacteria induce differential interferon- $\beta$ profiles in dendritic cells. Cytokine 56, 520-530. doi: 10.1016/j.cyto.2011.07.024
Weston, S., Halbert, A., Richmond, P., and Prescott, S. L. (2005). Effects of probiotics on atopic dermatitis: a randomised controlled trial. Arch. Dis. Child. 90, 892-897. doi: 10.1136/adc.2004.060673

Wickens, K., Black, P., Stanley, T. V., Mitchell, E., Barthow, C., Fitzharris, P., et al. (2012). A protective effect of Lactobacillus rhamnosus HN001 against eczema in the first 2 years of life persists to age 4 years. Clin. Exp. Allergy 42, 1071-1079. doi: 10.1111/j.1365-2222.2012. 03975.x

Wickens, K., Black, P. N., Stanley, T. V., Mitchell, E., Fitzharris, P., Tannock, G. W., et al. (2008). A differential effect of 2 probiotics in the prevention of eczema and atopy: a double-blind, randomized, placebocontrolled trial. J. Allergy Clin. Immunol. 122, 788-794. doi: 10.1016/j.jaci.2008. 07.011

Williams, H., and Flohr, C. (2006). How epidemiology has challenged 3 prevailing concepts about atopic dermatitis. J. Allergy Clin. Immunol. 118, 209-213. doi: 10.1016/j.jaci.2006.04.043

Williams, H. C., and Grindlay, D. J. (2008). What's new in atopic eczema? An analysis of the clinical significance of systematic reviews on atopic eczema published in 2006 and 2007. Clin. Exp. Dermatol. 33, 685-688. doi: 10.1111/j.1365-2230.2008.02906.x

Woo, S. I, Kim, J. Y., Lee, Y. J., Kim, N. S., and Hahn, Y. S. (2010). Effect of Lactobacillus sakei supplementation in children with atopic eczemadermatitis syndrome. Ann. Allergy Asthma Immunol. 104, 343-348. doi: 10.1016/j.anai.2010.01.020

Wu, K. G., Li, T. H., and Peng, H. J. (2011). Lactobacillus salivarius plus fructooligosaccharide is superior to fructo-oligosaccharide alone for treating children with moderate to severe atopic dermatitis: a double-blind, randomized, clinical trial of efficacy and safety. Br. J. Dermatol. 166, 129-136. doi: 10.1111/j.13652133.2011.10596.x

Yesilova, Y., Calka, O., Akdeniz, N., and Berktas, M. (2012). Effect of probiotics on the treatment of children with atopic dermatitis. Ann. Dermatol. 24, 189-193. doi: 10.5021/ad.2012.24.2.189

Yoshida, Y., Seki, T., Matsunaka, H., Watanabe, T., Shindo, M., and Yamada, N. (2010). Clinical effects of probiotic Bifidobacterium breve supplementation in adult patients with atopic dermatitis. Yonago Acta Med. 53, 37-45.

Conflict of Interest Statement: The authors declare that the research was conducted in the absence of any commercial or financial relationships that could be construed as a potential conflict of interest.

Copyright (C) 2016 Rather, Bajpai, Kumar, Lim, Paek and Park. This is an open-access article distributed under the terms of the Creative Commons Attribution License (CC BY). The use, distribution or reproduction in other forums is permitted, provided the original author(s) or licensor are credited and that the original publication in this journal is cited, in accordance with accepted academic practice. No use, distribution or reproduction is permitted which does not comply with these terms. 